\title{
The Canadian resident and
}

\section{fellowship competition in}

\section{respiratory disease}

Thad the honour recently to help organize a competition for residents and fellows with in interest in respiratory health.

Pediatric and adult training and rescarch programs in pulmonary and allergy medicine were each asked to choose the best project from a resident and from a fellow separately. The candidates chosen were invited to give an oral presentation of their project at Niagara-on-the Lake, Ontario as guests of Glaxo Canada, the sponsor of the competition.

The idea for the competition, which is entering its fourth year, originated in Toronto and must be crediced to Douglis Bradley, Ken Chapman and Art Slutsky. It allows young clinicians and scientists to gather together in an inlormal setting, make contacts that foster cooperative relationships in the luture and achieve early recognition for their work. The winner in each of the resident and fellow categories reccives a trophy as well as $\$ 1.500$ towards a trip to an international scientific meeting. The winner is announced at the annual Canadian Thoracic Society dinner held during the Royal College meetings. All candidates are also encouraged to present their abstracts at the scicntilic sessions of the Royal College annual meeting held a few days later.

A strength of the competition is the opportunity provided to all participants to ask questions and for the ciandidates to respond in detail, thus demonstratting their grasp of the field, but even more important, their vision of where the work is going. Credit for the quality of the discussion goes in large part to the judges who, this past year, were Dean Befus from Edmonton, Louis-Philippe Boulet from Quebec City and Douglas Bradley from Toronto. I am grateful for their hard work and their ability to combine a broad knowledge base with cquick insight. The heart of the competition is provided by the presentations, which range from clinical case reports to state of the art molecular biology. The quality of the science was far superior to what I expected, the poisc and clarity in presentations were, to me, remarkable, all of which augur well for the future of clinical and basic science research in respiratory diseases in Canada. My special congratulations to Carla Chrusch from Winnipeg and Thomas Waddell from Toronto, the winners in the resident and fellow categories, respectfully.

Dr Chrusch carried out a prospective study of bacterial colonization of the airway in intubated patients and the incidence of pneumonia. Dr Waddefl examined the role of L-selectin in the binding of neutrophils to endothelium at inflammatory sites.

The 1995 competition will be held in the Montreal area over two days just before the Royal College Meeting. Abstracts should be sent to me by June 3, 1995. I urge all program and laboratory directors to choose their best and send it along. The principal eligibility requirement is that the subject matter deal with respiratory health. We welcome residents, not only in pulmonary and allergy medicine, but also in pediatrics, internal medicine and thoracic surgery. Fellows can be either MDs or PhDs doing doctoral or post-doctoral training. This competition provides a unique opportunity to promote research in our field, and I count on all ol you to guarantee its continuing success.

Pierre Ernst MD

Respiratory Epidemitology Unit Me Gill University Mentreal, Quebere 


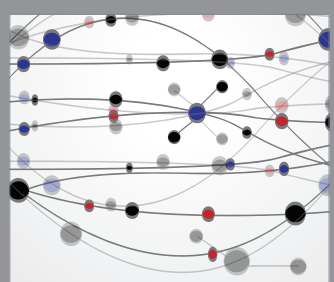

The Scientific World Journal
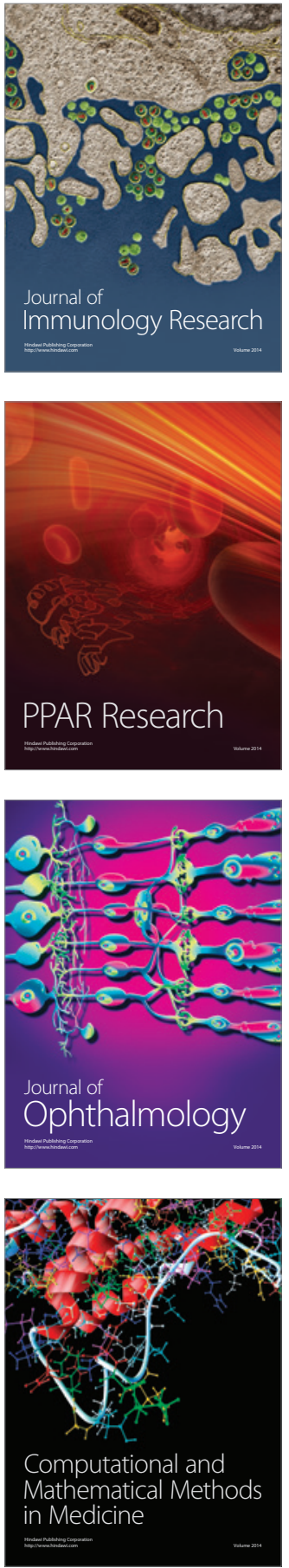

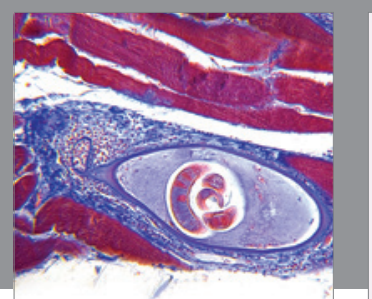

Gastroenterology Research and Practice

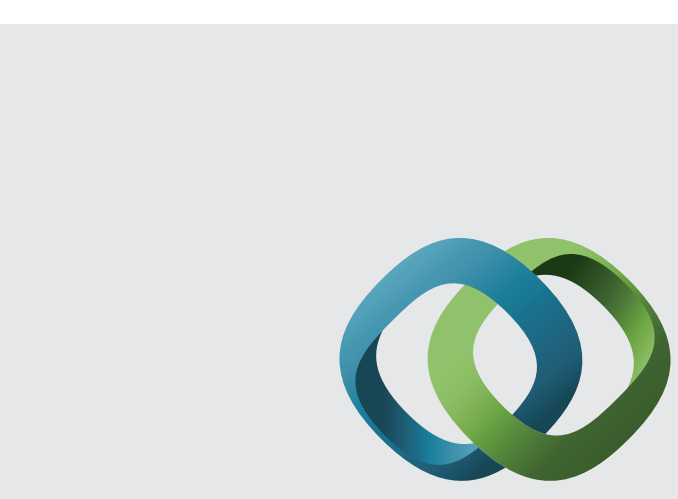

\section{Hindawi}

Submit your manuscripts at

http://www.hindawi.com
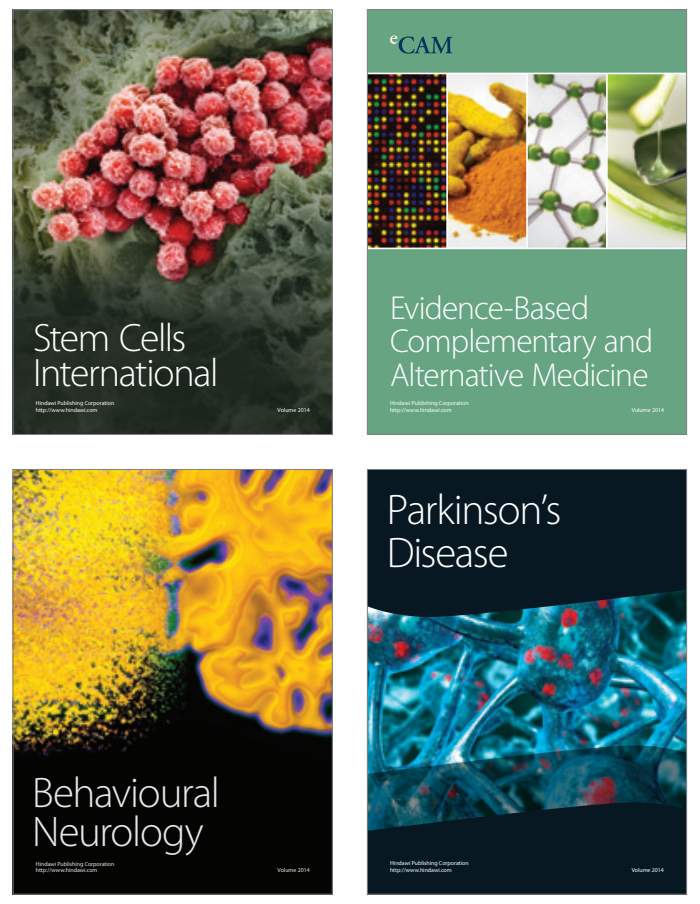
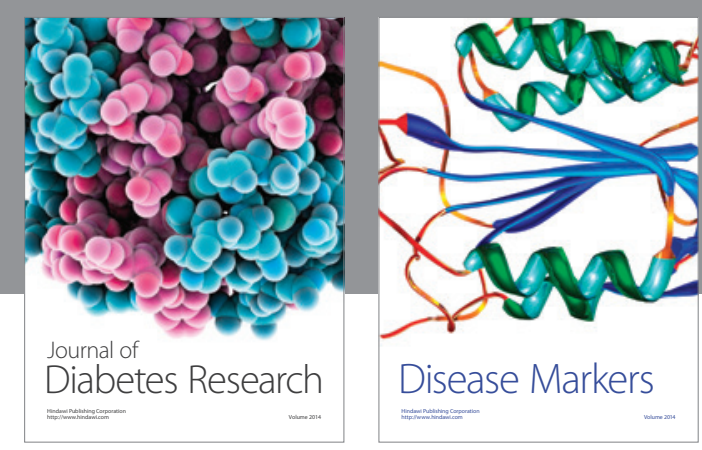

Disease Markers
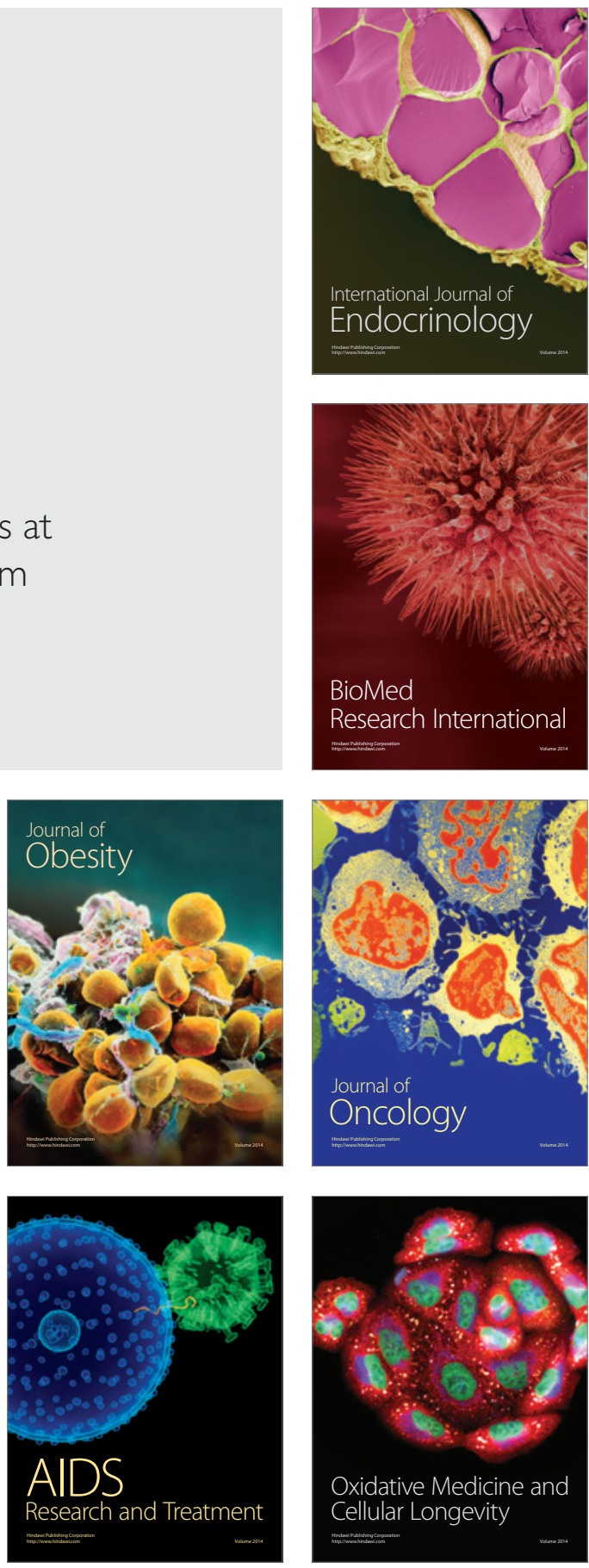